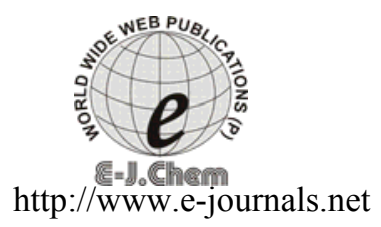

ISSN: 0973-4945; CODEN ECJHAO

E-Journal of Chemistry

2011, 8(S1), S318-S322

\title{
Synthesis, Characterization and Epoxidation of cis-Enriched New Polycarbonates Catalyzed by Efficient Organotin Compound
}

\author{
A. H. MASSOUDI ${ }^{\#}$, N. RAMAZANIAN ${ }^{\S}$, H. VAHEDI ${ }^{\#^{*}}$ and J. KHODABAKHSHI \\ ${ }^{\#}$ Chemistry Department, Payame Noor University, 19395-4697 Tehran, I. R. of Iran \\ ${ }^{\S}$ Chemnitz University of Technology, Institute of Chemistry \\ Organic Chemistry, Strasse der Nationen 62, 09111 Chemnitz, Germany \\ Khouzestan Petrochemical Company, Mahshahr, Iran \\ hooshangvahedi@yahoo.co.uk
}

Received 19 December 2010; Accepted 28 February 2011

\begin{abstract}
Presence of active functional groups on polymer chain is a suitable aspect of polymer structure which allows performing next favourite reactions on polymer molecule. In this research a novel aromatic derivative of cis-but-2endiol was synthesized as monomer. The synthesized monomer was polymerized using diphenyl carbonate and 1,4-butandiol as second and third monomer along with organotin catalyst. Polymerization reaction performed by using melt-phase transesterification process to produce a new terpolymer of polycarbonate. During the reaction the double bonds are preserved on polymer chain and epoxidized by $m$-chloroperbenzoic acid (MCBPA) in good yield to demonstrate the reactivity and possibility of performing further reactions on double bonds of polymer.
\end{abstract}

Keywords: Polycarbonates, Epoxidation, Cis-but-2-endiol derivative, Drug delivery systems

\section{Introduction}

Polycarbonates are versatile and extremely useful class of high heat engineering polymers known for their toughness and clarity which are widely commercialised and have been used in many routine and industrial applications. It can be utilized for making compact discs and DVDs, windows for airplanes and high-performance sport cars, bullet proof windows, medical purposes and so on. Most polycarbonates are made from phosgene in a two phase reaction ${ }^{1-4}$. However, despite of its significance in industrial applications the use of phosgene which has high toxicity and corrosiveness combined with expensive polycarbonate production on the relevant reactions involved are still very limited. A review was reported 
by Gross et al. on the use of in vitro enzyme catalysis for polyester and polycarbonate synthesis $^{5}$. Oxidative carbonylation of bisphenol A to polycarbonates has been studied using mixtures of carbon monoxide and oxygen in the presence of a host of catalytic systems ${ }^{6}$.

The aim of the present work is being to synthesis a novel polycarbonate which has a double bond on polymer chain and epoxidation of double bonds on synthesized polymer to show possibility of performing favourite reactions on these active sites on polymer chains. Therefore our work has three steps, synthesis of a phenolic aromatic derivative of cis-but-2endiol as monomer, polymerization of monomer to synthesis polycarbonate and finally epoxidation of double bonds on polymer chain.

\section{Experimental}

NMR spectra were recorded on a Varian Mercury $\left({ }^{1} \mathrm{H}=500 \mathrm{MHz} ;{ }^{13} \mathrm{C}=125 \mathrm{MHZ}\right) \mathrm{NMR}$ spectrometer. FT-IR spectra were measured on Bruker spectrometer.

\section{Synthesis of monomer (3)}

In a round bottom flask, a mixture of cis-1,4-but-2-endiol (50 mmol, 4.405 g), 4-hydroxy benzyl alcohol $4(100 \mathrm{mmol}, 12.414 \mathrm{~g})$ and $\mathrm{Yb}(\mathrm{OTf})_{3}(2 \mathrm{mmol}, 1.24 \mathrm{~g})$ in acetonitrile $(100 \mathrm{~mL})$ was stirred at $80{ }^{\circ} \mathrm{C}$ for $5 \mathrm{~h}$. After diluting with water $(100 \mathrm{~mL})$ the product extracted by ethyl acetate. Organic phase was washed with water and the solvent was removed by vacuum distillation to obtain the product. It can be purified by column chromatography or recrystallization (in ethanol). Yield of reaction is $70 \%$.

Aqueous phase can be used for recovery of catalyst. Recovered catalyst is effective enough for use in another synthetic reaction. IR (KBr) 3384, 1612, 1510, 1228, $778 \mathrm{~cm}^{-1}$; ${ }^{1} \mathrm{HNMR}(500 \mathrm{MHz}, \mathrm{DMSO}) \delta_{\mathrm{H}}=4.04\left(4 \mathrm{H}, \mathrm{OC}_{2} \mathrm{CH}=\right), 4.70\left(4 \mathrm{H}, \mathrm{ArC}_{2} \underline{\mathrm{H}}_{2} \mathrm{O}\right), 5.54(2 \mathrm{H}$, $\mathrm{C} \underline{H}=), 6.70-7.17$ (AA'XX', 8H, Ar- $\underline{\mathrm{H}}) \mathrm{ppm} ;{ }^{13} \mathrm{CNMR}(125 \mathrm{MHz}, \mathrm{DMSO}) \underline{\delta}_{\mathrm{C}}=57.8,63.4$, $129.8,115.8,130.3,131.3,153.6 \mathrm{ppm}$

\section{Synthesis of polymer (2)}

In a round bottom flask a mixture of 1,4-butandiol (11.36 mmol, $1.023 \mathrm{~g})$, diphenylcarbonate $(22.72 \mathrm{mmol}, 4.867 \mathrm{~g}), \mathrm{Bu}_{2} \mathrm{Sn}(\mathrm{OMe})_{2}(0.28 \mathrm{mmol}, 0.08 \mathrm{~g})$ and monomer $3(11.36 \mathrm{mmol}, 3.408 \mathrm{~g})$ was heated in $120^{\circ} \mathrm{C}$ for $1 \mathrm{~h}$. After that the phenol which was formed as a by product in polymerization reaction was extracted completely by vacuum for about $2 \mathrm{~h}$. The reaction mixture was cooled and dichloromethane $(10 \mathrm{~mL})$ was added to the mixture. By adding pre-cooled methanol $(90 \mathrm{~mL})$ at $0{ }^{\circ} \mathrm{C}$ (Ice cube) to the mixture a yellow polymer was precipitated out. The product was separated by centrifuge and dried in oven for 2h. IR (polymer film) 1745, $933 \mathrm{~cm}^{-1} ;{ }^{1} \mathrm{H}$ NMR (500 MHz, DMSO) $\delta_{\mathrm{H}}=1.72(\mathrm{~S}, 4 \mathrm{H}$, $\left.\mathrm{OC}(\mathrm{O}) \mathrm{CH}_{2} \mathrm{CH}_{2}\right), 3.47\left(\mathrm{OCH}_{2} \mathrm{CH}=\right), 4.12\left(\mathrm{~S}, 4 \mathrm{H}, \mathrm{OC}(\mathrm{O}) \mathrm{CH}_{2}\right), 4.75\left(\mathrm{~S}, 4 \mathrm{H}, \mathrm{Ar}_{-} \mathrm{CH}_{2} \mathrm{O}\right), 5.79$ $(\mathrm{S}, 2 \mathrm{H}, \mathrm{CH}=), 6.68-7.45\left(\mathrm{AA}^{\prime} \mathrm{XX}^{\prime}, 8 \mathrm{H}, \mathrm{Ar}-\mathrm{H}\right) \mathrm{ppm} ;{ }^{13} \mathrm{CNMR}(125 \mathrm{MHz}, \mathrm{DMSO}) \delta_{\mathrm{C}}=25.5$, $55.3,63.7,67.8,68.0,115.9,122.1,128.7,130.2,155.5$ ppm. $\mathrm{M}_{\mathrm{v}}=2977$

\section{Epoxidation of polymer 2 to the polymer 1}

In a round bottom flask, polymer $2(1 \mathrm{~g})$ was dissolved in methylene chloride. A minimum amount of tetrahydrofuran (THF) was added to contribute solubility and obtaining a homogeneous and clear polymer solution. Then, based on molecular weight of polymer or relative number of repeating units and double bonds on polymer chain, one equivalent $m$-chloroperbenzoeic acid was added and reaction mixture was refluxed at $50{ }^{\circ} \mathrm{C}$ for $24 \mathrm{~h}$. Finally the solvents were removed by rotary evaporator to precipitate the product which was 
washed three time by methanol and dried in oven for about $1 \mathrm{~h} .{ }^{1}$ HNMR data show $69 \%$ of double bonds have been epoxidized. IR (polymer film) same as polymer (2); ${ }^{1} \mathrm{HNMR}(500$ $\mathrm{MHz}, \mathrm{DMSO}) \delta_{\mathrm{H}}=1.65\left(\mathrm{~S}, 4 \mathrm{H}, \mathrm{OC}(\mathrm{O}) \mathrm{OCH}_{2} \mathrm{CH}_{2}\right), 3.36(\mathrm{~S}, 2 \mathrm{H}, \mathrm{CH}$ of epoxide), 4.10 (S, $\left.4 \mathrm{H}, \mathrm{OC}(\mathrm{O}) \mathrm{OCH}_{2}\right), 4.72\left(\mathrm{~S}, 4 \mathrm{H}, \mathrm{ArCH}_{2} \mathrm{O}\right), 5.77(\mathrm{~S}, 2 \mathrm{H}, \mathrm{CH}=), 6.64-7.56\left(\mathrm{AA}^{\prime} \mathrm{XX}^{\prime}, 8 \mathrm{H}\right.$, Ar- $\underline{\mathrm{H}}) \mathrm{ppm} ;{ }^{13} \mathrm{CNMR}(125 \mathrm{MHz}, \mathrm{DMSO}) \delta_{\mathrm{C}}=25.5,63.7,67.8,68.0,115.7,122.1,130.4$, $155.4 \mathrm{ppm}$.

\section{Results and Discussion}

The monomer (3) was synthesized from catalyzed etherification of cis-but-2-endiol and 4-hydroxy benzyl alcohol (4) in acetonitrile (Scheme 1). Kawada et al. reported ytterbium (III) trifluoromethanesulfonate as a suitable catalyst for etherification of benzyl alcohols ${ }^{7 \mathrm{a}}$. We found that this catalyst is suitable and effective in our reaction condition for the synthesis of monomer 3. The yield of the isolated product was about $70 \%$ and spectral investigations confirm the molecular structure of the expected monomer. The monomer exhibited a signal in the ${ }^{13} \mathrm{C}$ NMR spectrum at 57.8 and $63.4 \mathrm{ppm}$ for the methylene carbons, and showed absorption at $3384 \mathrm{~cm}^{-1}(\mathrm{OH}$ stretch) in the infrared spectrum.

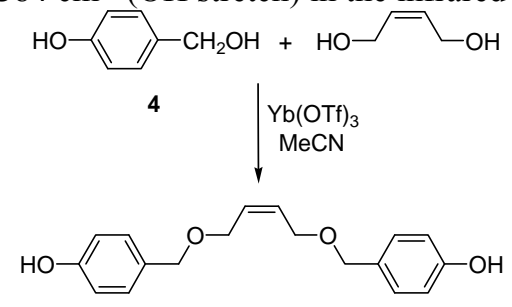

3

Scheme 1. $\mathrm{Yb}(\mathrm{OTf})_{3}$ Catalyzed etherification of 4 with cis-1,4-but-2-endiol.

For the polymerization of the synthesized monomer and preparing the expected polycarbonate the melt-phase transesterification method ${ }^{7 \mathrm{~b}}$ of diols with aromatic carbonates was carried out. Efficient and selective catalysts have to be employed for polymerization in such processes. In the literature, it is reported that basic catalysts such as alkali metals, alkaline earth metals and their oxides, hydrides, and amides, as well as basic metal oxides revealed high catalytic activity in the melt process ${ }^{8-10}$. Furthermore, a variety of patents claimed the use of organometal compounds ${ }^{8}$, especially organotin compounds ${ }^{11}$. Some experiments have shown that organotin compounds have lower catalytic activity than alkaline-earth metals (100-200 times lower), although utilizing it did not lead to drastic discolouration effects, which could be one of their advantages in industrial applications ${ }^{12}$. In this work dibutyldimethoxytin as a organometal catalyst was used to proceed polymerization reaction.

As shown in Scheme 2 the favourite polycarbonate is a terpolymer which has been produced from simultaneous polymerization of three different monomers. The spectral data confirm the polymer structure and show that the both aromatic synthesized derivative of cis-but-2-endiol and aliphatic 1,4-butandiol monomers are participated in polymerization reaction. In fact, synthesized polycarbonate consists of aromatic and aliphatic blocks and specially double bonds on polymer chain. The IR spectra of 2 exhibited the absorption bond of carbonyl group at $1745 \mathrm{~cm}^{-1}$ and ${ }^{1} \mathrm{H}$ NMR spectra showed signals at 1.72 and $4.12 \mathrm{ppm}$ arising from methylene groups of 1,4-butandiol moiety of the polymer. However, the absorbtion at $155.5 \mathrm{ppm}$ in ${ }^{13} \mathrm{CNMR}$ is a characteristic of carbonyl group and consistent with the structure of $\mathbf{2}$. 
<smiles>CO[PH2+](O)CO[Pb]c1ccc(COC/C=C\COCc2ccc(O)cc2)cc1</smiles><smiles>CCCC(=O)OCCCCOC(=O)Oc1ccc(COC/C=C\COCc2ccc(OC(C)C)cc2)cc1</smiles>

2<smiles>O=C(OO)c1cccc(Cl)c1</smiles><smiles>CCOc1ccc(COCC2OC2COCc2ccc(OC(=O)OCCCCOC(C)C)cc2)cc1</smiles>

Scheme 2. Dibutyldimethoxytin catalayzed polymersation of $\mathbf{3}$ with diphenyl carbonate and 1,4-butandiol following by epoxidation using MCBPA in dichloromethane

Double bonds on synthesized polymer induce some new chemical properties like more polarity, enhanced solubility in more polar solvents and also let us to perform favourite reactions on polymer. By this facility we would be able to add some functional groups or some molecules to polymer via reaction with double bonds. As Scheme 2 shows, synthesized polymer was epoxidized in the presence of MCBPA and dichloromethane at $50{ }^{\circ} \mathrm{C}$ for $24 \mathrm{~h} .{ }^{1} \mathrm{HNMR}$ and ${ }^{13} \mathrm{CNMR}$ confirm the structure of product $\mathbf{1}$ and presence of oxirane ring on polymer. Since not all of double bonds reacted to oxirane one can observe two separated peaks in ${ }^{1} \mathrm{HNMR}$ spectra, a peak for hydrogens of double bond at 5.79 and the other one for hydrogens of oxirane rings at $3.66 \mathrm{ppm}$. The percentage of oxirane ring in the polymer was $69 \%$, by integration of oxirane ring hydrogens peak to sum of integrations and multiply by 100 .

\section{Conclusion}

It was demonstrated that the etherification of cis-1,4-but-2-endiol with 4-hydroxy benzyl alcohol could add aromatic sections to monomer and it is possible to preserve functional groups during polymerization on polymer chain. This functional groups let us to proceed some favourite reaction on polymer for special purposes or special properties. In this work a typical reaction have shown that $\mathrm{C}-\mathrm{C}$ double bonds on polymer chain can be epoxidized to oxirane ring. Polycarbonates are used in drug delivery systems physically and without any chemical bond between drug and polymer ${ }^{13-16}$. Double bonds on this new polycarbonate make an opportunity to design drug carriers which can be chemically bonded to polymer.

\section{Acknowledgment}

We thank the Petrochemical Research and Technology Company (NPC-RT) from The Iranian National Petrochemical Company (NPC) for financial support of this work. 


\section{References}

1. Mathias L J and Carraher C G, Crown Ethers and Phase Transfer Catalysis in Polymer Science, Plenum Press, 1984.

2. Mikroyannidis J, Eur Polym J., 1985, 21, 895.

3. Tagle L and Diaz F R, Eur Polym J., 1987, 23,109.

4. Millich F, Carraher $\mathrm{C}$ and Marcel-Dekker, Interfacial Synthesis, Polymer Applications and Technology, 1977.

5. Gross R A, Kalra B and Kumar A, Appl Microbio.l Biotechnol., 2001, 55(6), 655-660

6. Skupińska J, Kuczyńska L and Wielgosz Z, React Kinetic Catal Let., 2003, 80, 269.

7. a) Kawada A, Yasuka K, Abe H and Harayama T, Chem Pharm Bill., 2002, 50, 380-383;

b) Ignatov V N, Tartari V, Carraro C, Pippa R, Nadali G, Berti C and Fiorini M, Macromol Chem Phys., 2001, 202, 1946-1949.

8. Freitag D, Grigo U, Muller P R and Nouvertne W, Encyclopedia of Polymer Science and Engineering, Wiley \& Son: New York, 1985.

9. Clagett D C, Shafer S J, Comprehensive Polymer Science, Bevington J C, Ed., Pergamon:Oxford, 1989.

10. Hsu J P and Wong J J, Ind Eng Chem Res., 2006, 45, 2672-2676.

11. Trapasso L E, Meisel P L, Meisel L B, Chwang W K, US Patent, 1997, 5606103

12. Ignatov V N, Tartari V, Carraro C, Pippa R, Nadali G, Berti C and Fiorini M, Macromol Chem Phys., 2001, 202, 1941-1945.

13. Garg R and Gupta G D, Pro Trop J Pharm Res., 2008, 7(3), 1055-1066

14. Umamaheshwari R B, Jain S, Bhadra D and Jain N K, J Pharm Pharmacol., 2003, 55, 1607-1613.

15. Joseph N J, Lakshmi S and Jayakrishnan A, J Control Rel., 2002, 79, 71-79.

16. Thanoo B C, Sunny M C and Jayakrishnan A, J Pharm Pharmacol., 1993, 45, 21-24. 


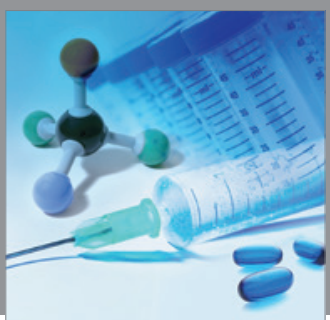

International Journal of

Medicinal Chemistry

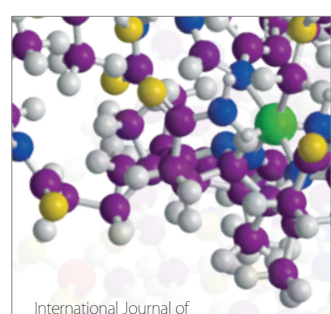

Carbohydrate Chemistry

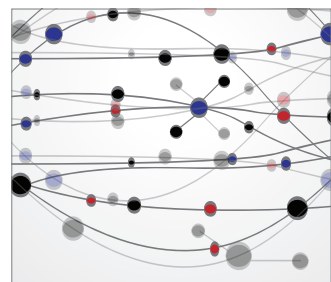

The Scientific World Journal
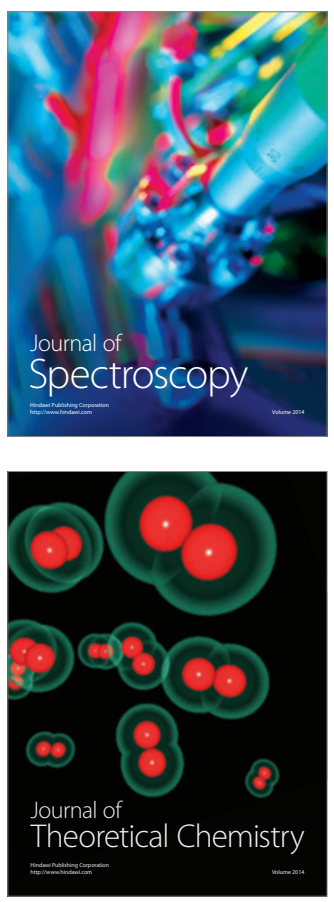
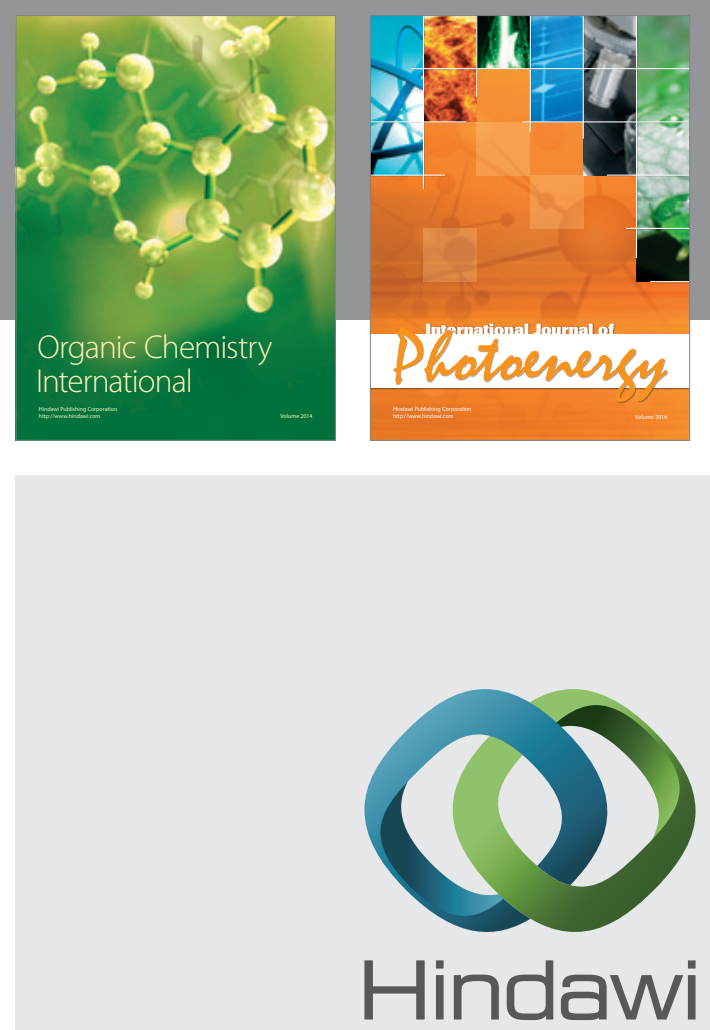

Submit your manuscripts at

http://www.hindawi.com
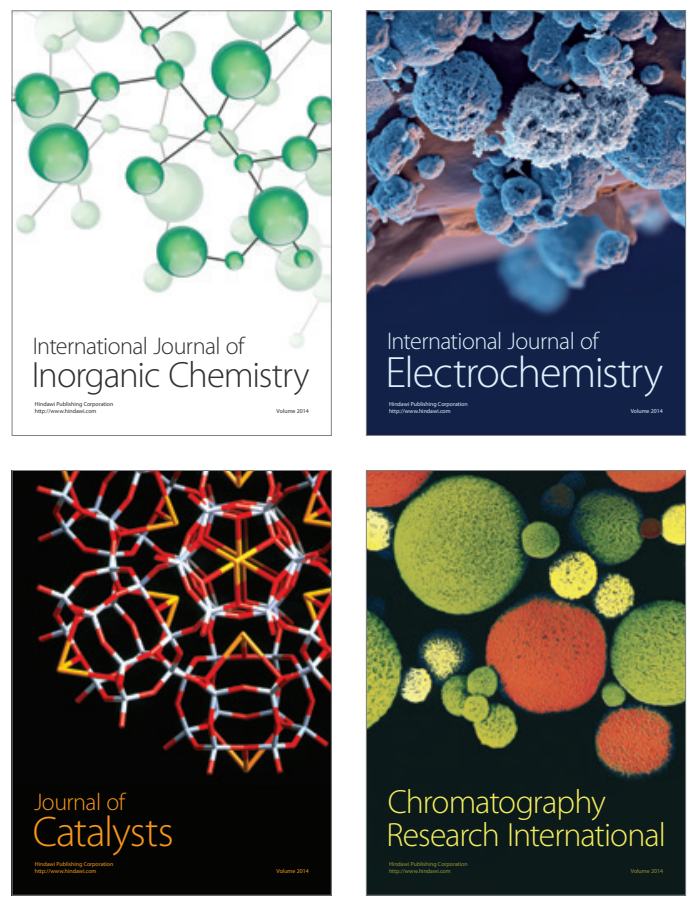
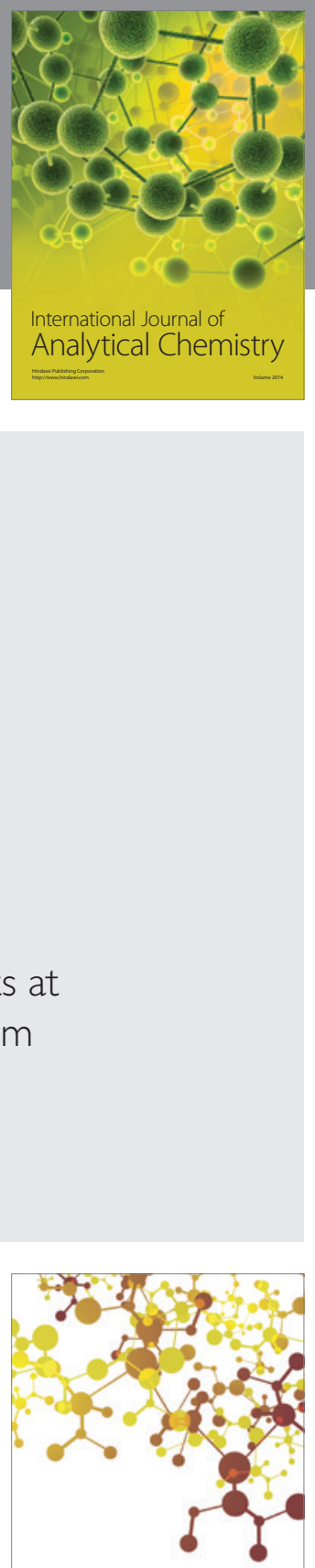

Journal of

Applied Chemistry
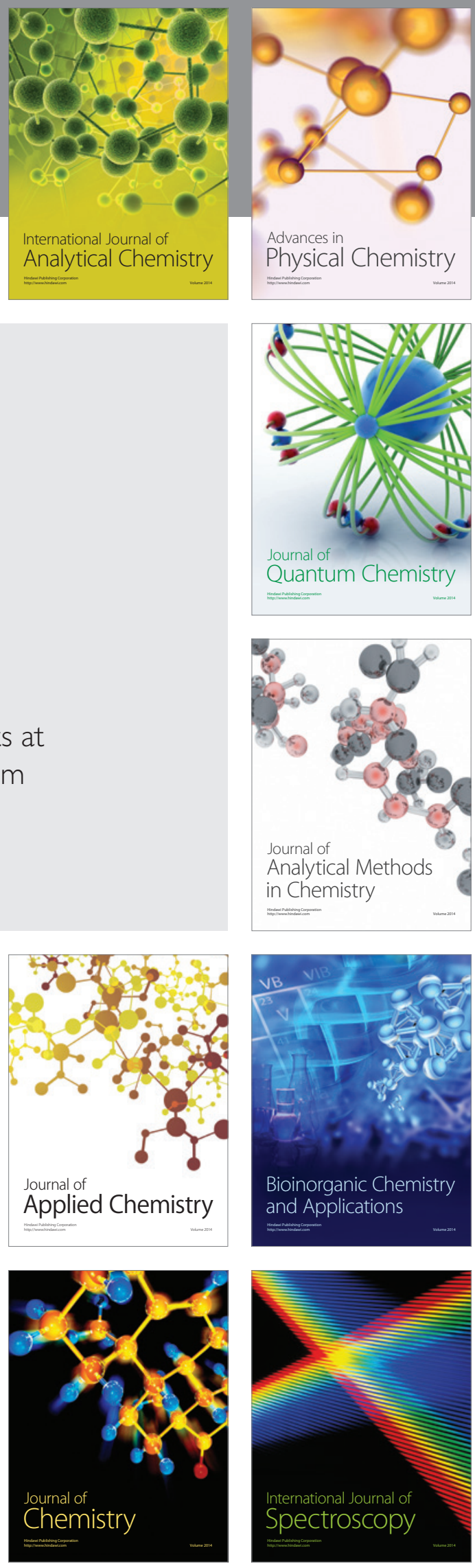